MedieKultur | Journal of media and communication research | ISSN 1901-9726

Book Review

\title{
Tula Giannini \& Jonathan P. Bowen (Eds.): \\ Museums and Digital Culture: New Perspectives and Research. Cham, Switzerland: Springer International Publishing. 2019
}

\author{
Eva Pina Myrczik
}

MedieKultur 2020, 68, 150-152

Published by SMID | Society of Media researchers In Denmark | www.smid.dk The online version of this text can be found open access at https://tidsskrift.dk/mediekultur

Since the introduction of digital technologies to museums in the 1990s, one of the main points of discussion has been the dichotomy between physical and digital experiences. In the first half of 2020 and continuing, museums worldwide have found themselves in a new reality where, due to direct orders to close their buildings to visitors due to the COVID-19 pandemic, the digital was not only one of many options to interact with the audience - it became their only reality. Yet, this new reality once again demonstrates the need for museums and scholarly discourse to explore the background, practice, and potential futures of such digital experiences.

Museums and Digital Culture seeks to discuss and find answers to crucial questions that will define the role and relevance of museums in the following years. Published in 2019, the editors could not have foreseen the heightened relevance of a book that sums up and introduces current discourses. Museums are identified as cultural institutions that react to external developments in societies and social change via activism and protest, as well as digitalization and digital culture in general. In the book, key researchers of digital heritage studies such as Ross Parry address current themes that frame the scholarly discourse on topics such as digital visitors. One chapter describes a case study exploring the use of chatbots in museum communication at four historic house museums in Milan, thereby addressing one of the currently most discussed emerging technologies in the field of cultural institutions. 
Moreover, growing insights on internal museum practices in transformation are highlighted. The volume addresses fields of ever-growing relevance, such as education for museum professionals, technology and art training in museums, the postdigital museum, collecting, documenting, and conserving digital art, and rethinking exhibitions, all of which shape internal progress in museums. Challenges as well as possible solutions are discussed in the individual book chapters, for instance, centering around how museum education can and eventually must adapt to this fast-paced environment of museum professionals and digital skills.

Just like the subject itself, the field of research on museums and digital culture is in constant development. The foreword to this volume by Loïc Tallon reminds us that "By virtue of living in the $21^{\text {st }}$ century, we are all students of digitization" (p. viii). Museums and Digital Culture picks up the reader as this student of digitization in both theory and practice. In his former role as Chief Digital Officer at the Metropolitan Museum of Art and as a researcher (Tallon \& Walker, 2008), the author of this quote has influenced the international digital museum world to a great extent. Now in 2020, he has already changed positions and left the museum world - which in itself highlights the fast-paced development and changes that this book seeks to explore.

Museums and Digital Culture is comprehensive in size (more than 500 pages), genres (scholarly research, conversations, artistic interventions and practice-based examples), and perspectives. The book does not stick to the usual boundaries of museum institutions but includes smart cities, research libraries, archives, and art practice. The editors do not explicitly mention who they imagine their readers to be. Yet, by "creating a body of evidence, so not a didactic approach, but rather one that inspires the reader to reconsider the new and evolving museum landscape" (p. 5), one can gather that the target group will be scholars, students, and practitioners of the art and museum field.

Based on their research, the editors address the underlying theoretical assumptions and developments that shape the scholarly and practice-based approaches to museums and digital culture in the framing chapters (e.g. Museums and Digitalism). Tula Giannini played a central role in researching and shaping developments by creating a Master's degree (bearing the same name as the book title) at the New York Pratt School of Information. Jonathan P. Bowen is an Emeritus Professor London School of Engineering, thus representing the computer science perspective. The book is closely connected to their scholarly practice, as they acknowledge that the annual EVA London Conference on Electronic Visualisation and the Arts has guided the selection of authors and themes, which reflects the wide spectrum of related fields that shape current discourses. This broadness in turn supports the editors' explorative approach, however the volume would have profited from more in-depth accounts that contribute to one unified argumentation.

Despite their initial caution, Giannini and Bowen attempt to envision the digital future of museums. One way to approach the future is by looking at the challenges that museums might face in their "grapple with audience perceptions of the past and the promise 
of the future" (p. 563). In the final chapter, the headline "prediction" naturally raises the reader's interest, yet as they remark, such "predictions are notoriously unreliable" (p. 557). In general, the editors' view on technology is rather optimistic, seeing and describing the potentials of the "digital ecosystem", while they situate the challenges in the realm of the museum world. Their approach is focused on the influence of technology and digital culture on museums and their visitors. In their preface to the book, the editors proclaim, "we have entered the next wave of the digital revolution" (p. xii). It is from this perspective of major change that the book sets out and presents the various angles and perspectives through which this transformation can be understood. This view is not uncommon in the literature about museums and emerging technologies; yet in 2019, one could expect a more balanced approach to the topic, which takes the more critical digital heritage research of the last ten years into account. Museums have collected more than 20 years of experience with digital technologies and culture and several practice-based studies have concluded that there still is a field of tension between the potentials and expectations towards technology versus the actual rather limited application of technology in the cultural context.

The inputs of the 25 additional contributors play an important role in portraying a more varied and insightful picture of artistic as well as museum practice and digital culture.

In the chapter Digital Culture Leaders Visioning the Postdigital Museum influential practitioners Seb Chan (ACMI Australia) and Courtney Johnston (Te Papa New Zealand) are found in conversation about the current (digital) practice at museums. Both practitioners have their main roles as responsible for audience experience and development, yet much of that role seems to be strongly tied to digital practice. The conversation is thought-provoking, as it explores exemplary career paths for digital museum leaders that started outside the museum world in tech and which have changed roles and positions in accord with museums and technology in flux.

At its core, Museums and Digital Culture encapsulates the current state of practice and research about the ways in which the development of technology and digital culture change both current and future museum and artistic practice. As such, the editors have chosen a fruitful variety of topics, trends, and theories that shape cultural institutions now and in the future.

Tallon, L., \& Walker, K. (Eds.). (2008). Digital Technologies and the Museum Experience: Handheld Guides and Other Media. AltaMira Press.

Eva Pina Myrczik PhD, Postdoc Department of Communication University of Copenhagen eva.myrczik@hum.ku.dk 